\title{
A EDUCAÇÃO NA COMPLEXIDADE CONTEMPORÂNEA
}

\author{
Ireno Antônio Berticelli ${ }^{1}$ \\ Romildo Ricardo Ramlow ${ }^{2}$
}

\begin{abstract}
RESUMO
O presente artigo propõe apresentar a pesquisa em educação na contemporaneidade numa perspectiva condizente aos avanços científicos. A partir do paradigma da complexidade, a pesquisa em educação e o próprio ato educativo exigem uma nova forma de pensar e organizar as instituições de ensino. Sem abandonar outras formas de pensar e ensinar, o paradigma da complexidade é uma proposta de pensar integradora, globalizante e múltipla. Numa sociedade pós-moderna, urge a necessidade de os educadores considerarem a complexidade como princípio pedagógico e pressuposto de todo conhecimento, uma vez que a educação sugere a complexa tensão entre conservação e inovação. Reconhecemos que não é possível estabelecer limites e conclusões em definitivo quando optamos por tratar da pesquisa em educação sob a ótica da complexidade. Este trabalho apenas teve a pretensão de tratar a educação na contemporaneidade em razão das exigências ante a realidade planetária e as demandas sociais, políticas e econômicas. A reforma do pensamento e das instituições foi e sempre será uma necessidade contemporânea de todos aqueles envolvidos com a educação, justificando a importância de novas perspectivas epistemológicas.
\end{abstract}

Palavras-chave: Paradigma. Pensamento. Conhecimento.

\section{THE EDUCATION IN CONTEMPORARY COMPLEXITY}

\section{ABSTRACT}

This article has as objetive to presente the research in education in contemporary times in a perspective consonante with the advances of sciences. From the paradigma of complexity, research in education and the act of education itself need a new way of thinking, teaching and organizing teaching institutions. Without setting aside other forms of thinking and teaching, the complexity paradigma is an integrative, globalizing and multiple proposal. In a postmodern society it is urgente the necessity of educators to consider the complexity as a pedagogic principle and presuposition of all knowledge, since education points out to the complex tension between conservation and inovation. We recognize that it is not possible to definitively establish limits and conclusions when we choose to deal with education research from the point of view of complexity. This work only had the pretension to treat the education in the contemporaneity due to the exigencies before the planetary reality and the social, political and economic demands. The reform of thought and institutions was and will always be a contemporary necessity of all those involved with education, justifying the importance of new epistemological perspectives.

Keywords: Paradigm. Thought. Knowledge.

RECEBIDO EM: 24/12/2017

ACEITO EM: 25/6/2018

\footnotetext{
${ }^{1}$ Doutor em Educação pela Universidade Federal do Rio Grande do Sul (UFRGS). ibertice@unochapeco.edu.br

${ }^{2}$ Mestre em Educação pela Unochapecó. Bacharel em Teologia pela Fatev e em Serviço Social pela Uniasselvi. romildo.ramlow@unochapeco.edu.br
} 


\section{PROLEGÔMENOS}

Na complexidade do mundo contemporâneo a educação precisa ser revista sempre de novo para, daí, compreendermos seu sentido antropológico com vistas a possíveis bifurcações teleológicas. Simplesmente repetir antigos modelos educativos, incompreensíveis pela maioria, já não dá mais conta das múltiplas demandas culturais. Novas tendências sociais e pedagógicas têm feito surgir questões desafiadoras para professores e alunos.

As inúmeras tentativas e formas de denominar a contemporaneidade têm possibilitado outras compreensões e a abertura para lidar com as crises na educação atual, marcada pela insistência de repetir modelos de tempos passados.

As tecnologias estão presentes tanto no cotidiano quanto nas salas de aula, o que fez Castells (1999) denominar esta época de "a sociedade em rede". Nos últimos 50 anos tivemos mais desenvolvimento inventivo (principalmente tecnológico) do que em toda a História da humanidade. Isso tem gerado oportunidades, avanços e inquietações.

De forma mais ampla, Bauman (2001) define a contemporaneidade como modernidade líquida, quando tudo é fluido e instável, e as relações humanas perdem consistência e estabilidade. Tal condição da sociedade tem gerado inúmeras crises no sistema educacional, inclusive quanto à forma homogeneizadora de educação (ciência tradicional, lógica desenvolvida a partir da Revolução Industrial).

O grande desafio na atualidade é pensar a educação numa sociedade instável, complexa e marcada pelas incertezas.

A proposta para estes desafios contemporâneos se expressa na virada linguística (linguistic turn), que traz a possibilidade de tratar a educação sob a ótica do pensamento complexo. $\mathrm{Na}$ atualidade já dispomos de boa referência de pesquisa no campo da complexidade e da auto-organização, a partir das pesquisas e publicações do professor Ireno Antônio Berticelli (2004, 2006, 2010), juntamente com um número crescente de educadores que se debruçam com competência sobre a matéria.

O modelo escolar atual, bem como sua prática pedagógica, são o resultado de paradigmas pedagógicos e visão de mundo, ou seja: inúmeros princípios idealistas resultaram em teorias e práticas pedagógicas perpetuadas e aceitas de forma inquestionável ao longo do tempo. Berticelli (2010) afirma que

[...] os paradigmas das ciências em geral influenciam de forma decisiva as propostas educacionais históricas. Um excurso pela história da educação nos mostra que as formulações paradigmáticas, em todos os tempos, fundamentaram pedagogias (p. 37).

Edgar Morin, em sua obra A cabeça bem-feita (2003a), observa acertadamente a inadequação grave entre os saberes fragmentados que geram, por sua vez, uma necessidade fundamental: a reforma do pensamento e das instituições.

Desta forma, a proposta será analisarmos a educação na perspectiva da transição paradigmática impulsionada pela cultura pós-moderna a partir da metáfora da liquidez em Bauman, para refletirmos sobre a condição e os possíveis caminhos da educação na contemporaneidade. De forma simultânea, faremos uma abordagem interdisciplinar 
com a chamada teoria da complexidade. O pensamento complexo contribui para um olhar sistêmico, aberto e que atravessa vários campos científicos, contribuindo para o desenvolvimento integral da natureza humana, sem pretendermos resolver todos os problemas, uma vez que Kant (2002) já enfatizava a educação como elemento da própria cultura, maior e o mais árduo problema que pode ser posto aos homens.

Nosso objetivo, portanto, é (re)pensar a educação a partir da teoria da complexidade no contexto da pós-modernidade.

\section{A EDUCAÇÃO (NÃO) SERVE...}

Para quê, afinal, a educação? Qual o propósito da educação? Como ela se articula ao longo do tempo? Essas e tantas outras perguntas devem ser feitas e respondidas por todos e sempre de novo. A capacidade de uma geração aprender, ou não, está diretamente ligada à (in)capacidade de ensinar do educador. Isso por que, "[...] não se pode dizer que alguém ensinou, se ninguém aprendeu" (LIMA, 1979, p. 18).

A partir de uma análise filosófica podemos afirmar que ensinar é um verbo bitransitivo e intransitivo, sendo necessário um objeto (direto ou indireto). Logo, como verbo bitransitivo, se alguém ensina, ensina alguma coisa (ensinar = verbo bitransitivo e intransitivo). Para ensinar alguma coisa, precisa-se conhecer o conteúdo ensinado. $\mathrm{E}$ quem ensina, ensina a alguém (verbo bitransitivo). Quem ensina algo é por que dispõe de um aprendiz. Somente há professor que ensinou se há aluno que aprendeu (educar como verbo bitransitivo). O sucesso em ensinar depende se alguém aprendeu e é apto a ensinar a outrem.

Buscando compreender a finalidade da educação é preciso que busquemos entender sua ontologia. Educação, do latim educere, significa extrair, tirar, desenvolver. Consiste na formação do caráter humano, afirma Brandão (2007). Constitui-se de processo auto-organizativo vital, conjugado pela interação consciente entre professor e aluno. Não é uma adaptação natural, de simples desenvolvimento ou crescimento. Intencionalmente, visa a levar os seres humanos a realizar suas potencialidades físicas, morais, espirituais e intelectuais. É um processo contínuo, que se inicia no nascimento e vai até a morte (BRANDÃO, 2007, p. 63-64).

Além de a educação servir para transmitir conceitos abstratos, ela serve a exigências sociais, formando pessoas na e para a sociedade. Serve para (re)produzir a ordem de cada sociedade, num momento da história. Por meio da inculcação de determinados saberes, visa a reproduzir tipos de sujeitos sociais. A educação é uma prática social servindo a ideias opostas:

[...] a educação é uma prática social (assim como a saúde pública, a comunicação social, o serviço militar) cujo fim é o desenvolvimento do que na pessoa humana pode ser aprendido entre os tipos de saber existentes em uma cultura, para a formação de tipos de sujeitos, de acordo com as necessidades e exigências de sua sociedade, em um momento da história de seu próprio desenvolvimento (BRANDÃO, 2007, p. 74). 
Ao contrário da finalidade básica de que o propósito da educação é desenvolver pessoas de forma integral em sua cultura e época, ela também tem sido instrumento para concretizar projetos de civilização, e ajuda-nos a entender os mecanismos civilizatórios no contexto da educação. Na perspectiva da teoria panóptica ${ }^{3}$ de Foucault (2012), a escola passa a utilizar a educação para fins de manipulação, regulação e disciplinamento, imposta sem questionamentos. Michel Foucault, ao estudar a sociedade disciplinar, constata que a sua singularidade reside na existência do desvio diante da norma. Por exemplo, para normalizar o sujeito moderno foi preciso desenvolver mecanismos e dispositivos de vigilância capazes de interiorizar a culpa e causar remorsos pelos seus atos. Cria-se, assim, um controle psicológico em que os indivíduos se autocontrolam, se fiscalizam e se comportam segundo a norma.

Qualquer forma de educação que monopoliza os saberes para fins civilizatórios resulta tão somente num processo dado, terminado; preocupa-se em apenas cuidar de sua continuidade e manutenção, a fim de configurar e legitimar o poder. Essa prática educativa gera imaturidade política e social que é proporcional ao grau de escolarização de nossa sociedade.

Como proposta para mudar essa lógica de homogeneização cultural, Kant lembra qual é a finalidade da educação:

A educação é uma arte, cuja prática necessita ser aperfeiçoada por várias gerações. Cada geração, de posse dos conhecimentos das gerações precedentes, está sempre melhor aparelhada para exercer uma educação que desenvolva todas as disposições naturais na justa proposição e de conformidade com a finalidade daquelas, e, assim, guie toda a humana espécie a seu destino (2002, p. 19).

A educação deve dispor das condições favoráveis a uma formação e preservação cultural que permita um modo de pensar aberto e livre. De outra forma, Piaget (1978) defende que a educação deve criar homens que sejam capazes de fazer coisas novas, não simplesmente repetir o que outras gerações já fizeram. Ainda, segundo Piaget (1978), a educação deve ser pensada de modo a que homens sejam criadores, inventores, descobridores. Devem-se formar mentes que estejam em condições de criticar, verificar e não aceitar tudo o que se propõe.

Esse desafio para com a educação na contemporaneidade tem sua causa na inadequação dos saberes fragmentados, e a realidade e seus problemas são cada vez mais transversais, multidisciplinares e planetários (MORIN, 2003a, p. 13).

Edgar Morin sugere uma reforma do pensamento como resposta a esses desafios, permitindo (re)ligar as culturas científicas dissociadas. Trata-se de uma reforma não pragmática, mas paradigmática, concernente a uma aptidão de organizar o conhecimento (p. 20).

A seguir vamos apresentar a proposta de Edgar Morin para a crise na educação contemporânea a partir da teoria da complexidade.

\footnotetext{
3 O panóptico era um edifício em forma de anel, no meio do qual havia um pátio com uma torre no centro. 0 anel dividia-se em pequenas celas que davam tanto para o interior quanto para o exterior. Em cada uma dessas pequenas celas havia, segundo o objetivo da instituição, uma criança aprendendo a escrever, um operário a trabalhar, um prisioneiro a ser corrigido, um louco tentando corrigir sua loucura e, na torre, havia um vigilante. 


\section{VISÃO COMPLEXA DA EDUCAÇÃO}

A educação na contemporaneidade requer uma abordagem alternativa à de outras épocas e que esteja sintonizada com o seu tempo e espaço. A contemporaneidade contém, em sua essência, a imprevisibilidade. As ciências tradicionais, caracterizadas pela regularidade, previsibilidade e verdades absolutas, não dão mais conta de responder às novas demandas da pós-modernidade. ${ }^{4}$ Surge, assim, a necessidade de novos paradigmas na educação que possibilitam atualizadas formas de pensar, conhecer e educar.

A educação precisa ser compreendida a partir da complexidade humana, da era planetária e das múltiplas ciências, possibilitando daí reflexões que sejam contextualizadas, integradoras e complementares por meio de um diálogo interdisciplinar, multidimensional e holístico. Morin destaca que precisamos de uma concepção complexa do sujeito (2003a, p. 128).

Repensar a educação é possibilitar a reforma do pensamento. Edgar Morin, precursor da gênese do pensamento complexo, sugere esse novo caminho por intermédio da teoria da complexidade. É um convite para que o pesquisador/cientista caminhe sem percurso predeterminado, rígido e previsível. Trata-se de uma nova concepção da realidade. Na sua essência, dispõe de pilares que envolvem a capacidade de conceber todas as coisas a partir do uno e do múltiplo.

Morin (2003a) entende que a vida intelectual não é separada da vida experimental. Essa concepção dicotômica, fragmentada e disciplinar da sociedade e, principalmente, da educação, tem sua origem na antiga Grécia. Desde então, como herança tradicional, a ciência se desenvolve nessa concepção binária: corpo e alma, profano e sagrado, visível e invisível, ordem e desordem, etc. Daí surgiu o paradigma simplificador da visão de mundo dualista, ainda mais reforçada a partir do século 17 pelo pensamento cartesiano (pensamento divisor). Ao contrário, na perspectiva da complexidade, sabe-se que quando um pesquisador busca compreender determinado fenômeno, este se envolve integralmente, com todas as facetas que compõem sua condição humana, ou seja: biológica, psíquica, física, social, afetiva, racional e cultural.

Segundo Vasconcellos (2007), "[...] o pensamento sistêmico como novo paradigma da ciência pode ser um passo inicial dessa mudança necessária", mas lembra de que se trata apenas de um convite para assumirmos uma nova visão de mundo e para constituirmos práticas novas, diferentes formas de nos relacionar, de estar e agir no mundo, que serão implicações inevitáveis ao assumir o pensamento sistêmico como o novo-paradigmático.

\footnotetext{
${ }^{4}$ Dada a pluralidade de expressões, tais como "pós-modernidade", "pós-estruturalismo", "modernidade líquida", "hipermodernidade" etc., há autores que preferem a expressão "contemporaneidade". Neste texto utilizamos o termo "pós-modernidade" honrando, até onde isto é possivel, todas essas expressões, cientes de que não são exatamente sinônimos.
} 
Numa visão sistêmica, complexa e multidimensional para a educação, faz-se necessário tomar consciência de que toda teoria é constituída da história de quem a propõe, de quem inclui seu modo de pensar, perceber, interpretar e compreender a realidade de modo único (SANTOS, 2015). Toda teoria e conhecimento científico é uma (re) construção/tradução de um pesquisador, de uma cultura e de um determinado tempo.

O paradigma científico clássico, cartesiano e hegemônico a que nos referimos anteriormente, está cedendo espaço ao paradigma da complexidade. Sem desmerecer as antigas formas de pesquisa, o pensamento complexo propõe uma complementariedade entre os paradigmas, não os desmerecendo, tampouco invalidando-os. Barcellos (2010) lembra o conceito de ruptura em Bachelard para assinalar a dupla descontinuidade histórica e epistemológica na história da ciência:

A contínua retificação dos conhecimentos anteriores é a chave de todo progresso científico. A ciência não é, pois, um conhecimento absoluto, nem rigoroso, mas apenas cada vez mais aproximado do sentido profundo da natureza. 0 progresso científico se faz por meio de sucessivas rupturas (BARCELLOS, 2010).

Bachelard propõe uma ruptura com as filosofias científicas imobilizadoras. Sua proposta para a compreensão dos problemas científicos contemporâneos é o novo espírito científico, defendendo que as formulações passadas devem dar lugar às novas construções do conhecimento. Nessa mesma direção, Edgar Morin propõe sua concepção de complexidade, apontando um futuro diferente para todas as ciências, questionando os mecanismos tradicionais de regulação, previsibilidade e verdade absoluta. Outros pensadores que contribuem com essa nova formulação paradigmática no mundo das ciências são: Heinz Von Foester, Francisco Varela, Humberto Maturana, Ilya Prigogine, Ludwig Von Bertalanffy, Henri Atlan, Humberto Mariotti, Ireno Antônio Berticelli entre outros.

A teoria da complexidade diz respeito não apenas à ciência, mas também à sociedade, à ética, à religião e à política. É, portanto, um problema de pensamento e de paradigma que envolve uma epistemologia geral, afirma Morin (2003b, p. 52). Segundo Minayo (2011), “[...] a teoria da complexidade é um termo genérico para explicação convergente de vários movimentos epistemológicos da ciência contemporânea".

A educação, numa perspectiva da complexidade, sugere repensá-la no contemporâneo sob novas possibilidades teóricas e metodológicas. Em seu livro $O$ fim da certeza, Prigogine (2003) justifica essa abordagem pelo fato de que a humanidade e a ciência estão em transição. A noção de complexidade neste contexto de crise e incertezas abre bifurcações que supera os determinismos e ideias de regularidade, estabilidade e equilíbrio (MINAYO, 2011).

Essa abordagem teórica, filosófica e metodológica da complexidade é sustentada por Morin, ao criticar a visão de mundo cartesiano e a necessidade de nova forma de olhar para a realidade social e humana por parte de pesquisadores, educadores e alunos.

Essa realidade a ser percebida é descrita da seguinte forma por Bauman: 
[...] o mundo tal como o conhecíamos, ou pensávamos conhecer, está saindo dos eixos. Está acelerando a cada dia e, em tempo real, a cada dia ficando menor. As antigas certezas desapareceram. Os velhos remédios não funcionam. As velhas e confiáveis pranchetas permanecem desocupadas ou produzem cópias de antigas plantas, como que num transe sonambúlico (2013, p. 121).

Na contemporaneidade, em razão das inúmeras complexidades epistemológicas, surgem desafios para a educação no âmbito teórico e prático. Mario Sergio Cortella (2014, p. 69) chama a atenção para o fato de que "[...] boa parte dos nossos alunos é do século 21, os professores do século 20 e os métodos do século 19". Existe, assim, um desencaixe de pelo menos três séculos de pensamento científico.

Esse descompasso histórico, somado aos paradigmas que não dão mais conta da crise de sentido que se amplia em virtude da crescente complexidade e incerteza que dominam os horizontes da vida contemporânea, exige um exame rigoroso das formas tradicionais de pensar, pesquisar, ensinar e aprender.

Diante da tentativa de tornar prático o pensamento complexo, Minayo (2011) aponta para o risco da banalização e ilusão ao aproximar áreas distintas do conhecimento de forma indiscriminada. Reforçando, Minayo assevera que "[...] há muito a caminhar em relação ao desenvolvimento prático do pensamento complexo" (p. 53).

Ainda carecemos de exemplos de tentativas de tornar prática a teoria da complexidade. De forma tímida, isso vem ocorrendo nas áreas da saúde, administração, psicologia e gestão de empresas. Numa abordagem no campo das ciências sociais e humanas, podemos citar o trabalho de Castells - A sociedade em rede (1999).

No contexto brasileiro, Humberto Mariotti, médico e psicoterapeuta na década de 70 do século 20, teve contato pela primeira vez com a chamada ciência da complexidade. Desde 1994 coordena grupos institucionais de estudos em Teoria da Complexidade, com o propósito de difundir esse conhecimento. Humberto Mariotti é autor dos seguintes títulos: Organizações de aprendizagem: educação continuada e a empresa do futuro (1999), As paixões do ego: complexidade, política e solidariedade (2000), Pensamento complexo: suas aplicações à liderança, à aprendizagem e ao desenvolvimento sustentável (2010a), Pensando diferente: para lidar com a complexidade, a incerteza e a ilusão (2010b) e Complexidade e sustentabilidade: o que se pode e o que não se pode fazer (2013), e, ainda, diversos artigos e ensaios.

Mais especificamente no campo da educação, a teoria da complexidade tem sido pesquisada por Hugo Assmann, com as obras Metáforas novas para reencantar a educação (1996) e Reencantar a educação: rumo à sociedade aprendente (1998). Outro autor que tem pesquisado e publicado sobre a teria da complexidade no campo educacional é Ireno Antônio Berticelli, doutor em educação e epistemólogo. Suas obras, fruto das pesquisas de Mestrado e Doutorado em Educação e outros estudos são: A origem normativa da prática educacional na linguagem (2004), Educação em perspectivas epistêmicas pós-modernas (2010) e Epistemologia e educação: da complexidade, auto-organização e caos (2006). 
É possível perceber o crescente interesse pelo pensamento complexo como abordagem paradigmática nas pesquisas científicas. Lima et al. (2014), em análise da obra de Minayo $O$ desafio do conhecimento (2013), destacam a importância do pensamento complexo na pesquisa científica contemporânea da seguinte forma:

[...] o pensamento complexo sintetiza os avanços teóricos e metodológicos de várias ciências e novos rumos do pensamento social, tangenciado por profundas mudanças no chamado mundo pós-industrial ou pós-moderno. Apresenta formas alternativas de tratar o objeto de investigação, a vida, o mundo, as práticas sociais e, sobretudo, as implicações do investigador com seu objeto de pesquisa. Suas dimensões epistemológicas são a complexidade, a instabilidade e a intersubjetividade. Abrange discussões multidisciplinares e multiprofissionais e não conflita com os recursos da ciência tradicional, propondo o exercício de um olhar e de uma abordagem diferente (p. 4).

Conforme o pensamento complexo vem sendo aplicado às ciências, percebe-se que não se trata de uma novidade apenas metodológica; antes, em parceria com as ciências tradicionais, busca de forma inter-multi-transdisciplinar observar, investigar e entender a realidade numa perspectiva integradora, pois, segundo Morin (2003a, p. 115), “[...] são os complexos de inter-multi-trans-disciplinaridade que realizaram e desempenharam um fecundo papel na história das ciências [...]". Isso exige uma mudança de paradigma do pensamento educacional.

\section{MUDANÇA DE PARADIGMA NA EDUCAÇÃO}

A teoria da complexidade pressupõe a incerteza de todas as atividades humanas. Essa incerteza exige novos modos de pensar. Em sua obra As ideias têm consequências (2012), Richard M. Weaver diagnostica as doenças de nossa época lançando mão de antigas concepções (por exemplo, o método de Descartes). Ele afirma que o mundo é inteligível e que o homem é livre, que as catástrofes e os desafios humanos não são produto da necessidade, mas de decisões pouco sábias. Como solução, sugere uma atitude realista. Ela encontra-se no uso correto da razão, diz Weaver, na renovada aceitação de uma realidade absoluta e no reconhecimento de que as ideias - como as ações - têm consequências.

Numa lógica de pensar complexo, entendemos que

Os atuais problemas da humanidade não podem ser resolvidos com base nos enfoques fragmentados que caracterizam nossas instituições governamentais e acadêmicas, gerados por modelos culturais ou conceituais obsoletos e variáveis irrelevantes.

Se a realidade é complexa, ela requer um pensamento abrangente, multidimensional, capaz de compreender a complexidade do real e construir um conhecimento que leve em consideração essa mesma amplitude (MORAES, 2012, p. 30).

Na educação existem muitos paradigmas cristalizados - manias, costumes e tradições -, os quais determinam atitudes sem maiores reflexões. Aprendemos e ensinamos a fazer determinadas coisas e de determinada maneira - uma vez aprendido -, repetindo o método sempre da mesma forma, acreditando que é assim mesmo que se deve fazer. 
Os paradigmas, como estruturas de pensamento, governam a visão das coisas e do mundo, são inscritos culturalmente nos seres humanos, regulam e determinam inconscientemente o modo de ser, conhecer, saber e agir (SANTOS, 2015). Desta forma, os paradigmas podem, ao mesmo tempo, estabelecer limites e referenciais de segurança pessoal e institucional ou serem transformados em bloqueios para projetos que beneficiariam milhares de pessoas. É preciso considerar o seguinte: ninguém vive sem paradigmas. Precisamos de regras para viver. Por isso é importante rever constantemente as ideias, crenças e valores que operam sob as ações no campo educacional, e analisar se elas são e ainda estão compatíveis com a realidade. Segundo Edgar Morin, a ciência liberta, não aprisiona.

Não necessariamente os paradigmas são algo negativo, pois eles constituem fronteiras dentro das quais as pessoas agem. Um paradigma torna-se negativo quando ele não cumpre o seu propósito, sendo necessário quebrá-lo e descobrir outros novos paradigmas.

Para Morin (2003a), um paradigma impera sobre as mentes porque institui os conceitos soberanos (disjunção ou conjunção), um tipo de relação dominadora que determina o curso de todas as teorias, dos discursos e práticas científicas. Desta forma, em direção a uma visão de mundo que dê conta da complexidade humana e supere a redução e fragmentação da realidade, Morin defende a mudança de mente e das instituições.

Morin (2003a) entende que, a fim de superar os diversos problemas da educação, é preciso que os professores superem um duplo bloqueio: reformar as mentes e, consecutivamente, as instituições. $O$ grande impasse é que não se pode reformar a instituição sem reformar a mente, e não se pode reformar a mente sem reformar as instituições. Para acontecer estas reformas, existem inúmeras resistências.

Há resistências inacreditáveis a essa reforma, a um tempo, una e dupla. A imensa máquina da educação é rígida, inflexível, fechada, burocratizada. Muitos professores estão instalados em seus hábitos e autonomias disciplinares. Estes [...] são como os lobos que urinam para marcar seu território e mordem os que nele penetram. Há uma resistência absoluta, inclusive entre os espíritos refinados. Para eles, o desafio é invisível (2003a, p. 99).

Sem essa dupla reforma (mente e instituições), Morin (2003a) acredita que quanto mais a crise progride, maior a incapacidade de pensar a crise. Como indicativo para a solução dessa crise, Morin sugere que seja reformado o ensino para que seja reformado o pensamento e que seja reformado o pensamento para que seja reformado o ensino. Esta proposta de reforma do pensamento não parte do zero no sentido de ignorar a história do pensamento científico. Visa justamente a uma concepção do termo complexus, que significa tecido junto, ou seja, conceber um novo paradigma cultural, abrangente, que seja condizente com o avanço da ciência, com a pós-modernidade e as tecnologias. Tal mudança deve iniciar pelos professores.

A necessidade de uma nova forma de pensamento é urgente, a fim de estabelecer outras maneiras de pensar a educação e superar as inadequações entre o conservador e o mundo emergente. Isso é necessário porque 
Vivemos num tempo atônito que ao debruçar-se sobre si próprio descobre que os seus pés são um cruzamento de sombras, sombras que vêm do passado que ora pensamos já não sermos, ora pensamos não termos ainda deixado de ser, sombras que vêm do futuro que ora pensamos já sermos, ora pensamos nunca virmos a ser (SANTOS, 2010b, p. 13).

Boaventura de Sousa Santos (2010b) aponta para uma mudança de paradigmas na atualidade, quando já está acontecendo uma ruptura da antiga forma iluminista de ver a vida e o mundo a partir de uma nova concepção científica. $O$ passado tem sua importância e valor, mas é preciso reconhecer seu limite, evitando estagnação por meio do continuísmo teórico-metodológico.

Paulo Freire já alertou que ensinar exige risco, aceitação do novo e rejeição de qualquer forma de preconceito e discriminação do velho. "[...] o velho que preserva sua validade ou que encarna uma tradição ou marca uma presença no tempo continua novo" (FREIRE, 2014, p. 36). Tal possibilidade poderá vir a se tornar real quando se pensa sobre a prática de outros tempos de forma contextualizada, buscando compreendê-la sob a ótica da complexidade, quando a educação busca ao mesmo tempo conservar e transformar o ser humano em seu propósito antropológico, sob uma ética e estratégia coerente e universal.

\section{CONSIDERAÇÕES FINAIS}

Uma das significativas vantagens dos seres humanos é a de ir mais além de seus condicionantes (FREIRE, 2014). Superar antigos paradigmas educacionais e compreender a educação no mundo contemporâneo é tarefa árdua, mas perfeitamente possível, pois um dos maiores educadores do século 20 observou que:

Mudar a escola [...] implica um trabalho profundo e sério com os educadores que tem a ver com a questão ideológica, com o assumir compromisso, com a qualificação dos profissionais e este caminho é, no meu entender, a dificuldade maior a transpor. Não considero também que seja uma dificuldade intransponível (FREIRE, 2001, p. 97).

Freire é realista em relação a mudanças na educação. É uma tarefa difícil, mas possível quando assumida com compromisso e que contemple a ética universal do ser humano. É preciso, por meio dos novos desafios do século 21, que todos os envolvidos em pesquisa e educação se mobilizem em prol de uma nova cultura educacional criativa, inovadora e contextual, permitindo a professores, alunos e instituições desenvolverem juntas aquilo que Cláudio Almir Dalbosco chama de "cidadania democrática". ${ }^{5}$

\footnotetext{
${ }^{5}$ DALBOSCO, Cláudio Almir. Ética e ciência na educação Superior: formação para a cidadania democrática. In: REZER, Ricardo (Org.). Ética e ciência na educação Superior. Chapecó: Argos, 2013. Dalbosco destaca três pilares que sustentam a formação para a cidadania democrática: a) pensamento crítico; b) cidadania universal; c) imaginação narrativa. Lembra que a educação mais adequada para as novas gerações, no sentido de prepará-las ao bem viver em sociedades plurais, marcadas por formas diversificadas de vida, é aquela baseada nas ideias da cidadania democrática. A educação que acentue somente os aspectos científicos e tecnológicos na formação de profissionais não estimula as novas gerações para estudar dimensões mais amplas da cultura. A construção de tais pilares não é tarefa somente da educação Superior, e nem pode ser reduzida apenas a atividades curriculares da educação formal. Elas devem ser incorporadas culturalmente no modo de ser e viver das pessoas e da sociedade como um todo.
} 
A educação precisa de novos paradigmas. Boaventura de Souza Santos (2010b, p. 83) lembra que "[...] a ciência moderna não é a única explicação possível da realidade e não há sequer uma razão científica para considerá-la melhor que as explicações alternativas da metafísica, da astrologia, da religião, da arte ou da poesia". Os saberes emergentes sugerem um paradigma alternativo.

A mudança da modernidade para a pós-modernidade exige novas formas de ensinar, pois não se vive, convive, estuda, trabalha, como antigamente. A transição paradigmática precisa ser gestada para que o conhecimento possa ser construído constantemente em meio à realidade complexa, socialmente flutuante e metodologicamente diversa.

Segundo Edgar Morin (2003a), a educação na contemporaneidade precisa fomentar coletivamente uma cabeça bem-feita que, em vez de acumular o saber, professores e alunos disponham ao mesmo tempo de uma aptidão geral para colocar e tratar as questões biopsicossociais, e saibam ligar os saberes e lhes dar sentido.

A educação como processo de formação humana cumprirá sua finalidade quando servir de libertação dos antigos costumes, tradições, ideias, formas e hábitos escravizadores. Tomando como exemplo Platão, a partir de uma ressignificação do mito da caverna, ele poderia sugerir, de forma alegórica, que o mundo real e complexo das formas e ideias em que a educação está inserida poderia assegurar a liberdade aos professores e alunos mediante uma cabeça bem-feita.

Reconhecemos que não é possível estabelecer limites e conclusões em definitivo quando optamos por tratar da pesquisa em educação sob a ótica da complexidade. Este trabalho apenas teve a pretensão de tratar a educação na contemporaneidade em virtude das exigências diante da realidade planetária e das demandas sociais, políticas e econômicas. A reforma do pensamento e das instituições foi e sempre será uma necessidade contemporânea de todos aqueles envolvidos com a educação, justificando a importância de novas perspectivas epistemológicas. Este é, antes de mais nada, um ponto de partida possível.

\section{REFERÊNCIAS}

ASSMAN, Hugo. Reencantar a educação: rumo à sociedade aprendente. Petrópolis: Vozes, 1998. . Metáforas novas para reencantar a educação. Piracicaba: Unimep, 1996.

BAUMAN, Zygmunt. Sobre educação e juventude. Rio de Janeiro: Zahar, 2013. Modernidade líquida. São Paulo: Zahar, 2001.

BARCELLOS, Ana C. Kastein. A importância de Gaston Bachelard na formação do espírito científico. 2010. Disponível em: <http://www.unimep.br/phpg/mostraacademica/anais/8mostra/5/526.pdf>. Acesso em: 23 jan. 2015.

BERTICELLI, Ireno Antônio. Ética do discurso: uma possibilidade em pesquisa. In: REZER, Ricardo (Org.). Ética e ciência na educação Superior. Chapecó: Argos, 2013. Educação em perspectivas epistêmicas pós-modernas. Chapecó: Argos, 2010.

Epistemologia e educação: da complexidade, auto-organização e caos. Chapecó: Argos, 2006.

A origem normativa da prática educacional na linguagem. Ijuí: Ed. Unijuí, 2004.

BRANDÃO, Carlos Rodrigues. O que é educação. São Paulo: Brasiliense, 2007.

CASTELLS, M. A sociedade em rede. São Paulo: Paz e Terra, 1999.

CORTELLA, Mario Sergio. Educação, escola e docência. São Paulo: Cortez, 2014. 
DALBOSCO, Cláudio Almir. Ética e ciência na educação Superior: formação para a cidadania democrática. In: REZER, Ricardo (Org.). Ética e ciência na educação Superior. Chapecó: Argos, 2013.

FREIRE, Paulo. Pedagogia da autonomia. 49. ed. Rio de Janeiro: Paz e Terra, 2014. . A educação na cidade. 5. ed. São Paulo: Cortez, 2001.

FOUCAULT, Michel. Vigiar e punir: nascimento da prisão. Petrópolis: Vozes, 2012.

KANT, Immanuel. Sobre a pedagogia. 4. ed. Piracicaba: Editora Unimep, 2002.

LIMA, Aline Cristina da S. et al. O desafio do conhecimento. Revista Eletrônica Inter-Legere, n. 14, jan./jun. 2014 (Resenha). ISSN 1982 -1662.

LIMA, Lauro de Oliveira. Mutações em educação segundo McLuhan. 12. ed. Petrópolis: Vozes, 1979.

MARIOTTI, Humberto. Complexidade e sustentabilidade: o que se pode e o que não se pode fazer. São Paulo: Atlas, 2013.

Pensamento complexo: suas aplicações à liderança, à aprendizagem e ao desenvolvimento sustentável. 2. ed. São Paulo: Atlas, 2010a. 2010b. Pensando diferente: para lidar com a complexidade, a incerteza e a ilusão. São Paulo: Atlas, As paixões do ego: complexidade, política e solidariedade. São Paulo: Palas Athena, 2000. 1999.

Organizações de aprendizagem: educação continuada e empresa do futuro. São Paulo: Atlas,

MINAYO, Maria Cecília de Souza. Da inteligência parcial ao pensamento complexo: desafios da ciência e da sociedade contemporânea. Revista Política \& Sociedade, Florianópolis, v. 10, n. 10, out. 2011. Disponível em: <https://periodicos.ufsc.br/index.php/politica/article/view/2175-7984.2011v10n19p41>.

O desafio do conhecimento: pesquisa qualitativa em saúde. 13. ed. São Paulo: Hucitec, 2013.

MORAES, Maria Cândida. Os paradigmas educacionais emergentes. 16. ed. Campinas: Papirus, 2012.

MORIN, Edgar. A cabeça bem-feita: repensar a reforma, reformar o pensamento. 8. ed. Rio de Janeiro: Bertrand Brasil, 2003a.

Educar na era planetária. São Paulo: Cortez, 2003b.

PIAGET, Jean. A formação do símbolo na criança: imitação, jogo e sonho, imagem e representação. 3. ed. Rio de Janeiro: Zahar, 1978.

PRIGOGINE, Ilya. O fim das certezas: tempo, caos e as leis da natureza. São Paulo: Editora Unesp, 2003.

SANTOS, Boaventura de Sousa. Conhecimento prudente para uma vida decente. São Paulo: Cortez, 2010a. Um discurso sobre a ciência. 7. ed. São Paulo: Cortez, 2010 b.

SANTOS, Silvana S. Costa. A complexidade e a religação do pensamento interdisciplinares: contribuição do pensamento de Edgar Morin. Disponível em: <http://www.scielo.br/pdf/reben/v65n4/a02v65n4.pdf>. Acesso em: 20 jan. 2015.

VASCONCELLOS, M. J. Pensamento sistêmico, o novo paradigma da ciência. São Paulo: Papirus, 2007.

WEAVER, Richard M. As ideias têm conseqüências. São Paulo: É Realizações, 2012. 